\title{
Evaluating the CBM reservoirs using NMR logging data
}

https://doi.org/10.1515/geo-2018-0043

Received June 7, 2017; accepted March 8, 2018

\begin{abstract}
This paper discussed the application of nuclear magnetic resonance (NMR) logging in evaluating the pore structure of coal seams, physical properties, aquosity and sealing of the coal seam roof and floor. The study results show that $\mathrm{T}_{2}$ relaxation time spectrum could reflect the pore structure characteristics of the coal. The NMR transverse relaxation time $\left(\mathrm{T}_{2}\right)$ of coal is $0.5 \sim 2.5,20 \sim 50$, and more than $100 \mathrm{~ms}$, three spectral peaks represent meso pores, large pores and fractures. The larger the spectral peaks are where more pores and fractures develop. The $\mathrm{T}_{2}$ relaxation time spectrum of coal reservoirs in the research area is generally characterized by double-peak structure characteristics, which shows that the coal reservoir is microporous with meso pores. There are obvious gaps and poor continuities between the two peaks, and the break point is approximately $10 \mathrm{~ms}$ between the two peaks point. This indicates that the bound water and movable fluid in the coal reservoir cannot be connected effectively. NMR can reflect the level of porosity and permeability of the coal reservoir. Greater development of fracture and better permeability in the coal reservoir cause greater right peak of $T_{2}$ relaxation time spectrum of the NMR. The effective porosity of coal reservoirs in the study area is generally less than 3\%, which reflects the matrix pores of the coal seam. The fractures of large pore have little contribution to the porosity. The left peak of the $\mathrm{T}_{2}$ spectrum of a coal seam and its roof and floor are higher, which indicates that the meso pores and tiny pores develop, and there is less movable water. The low left peak and high right peak of $\mathrm{T}_{2}$ spectrum show that the meso and macro pores develop, and there is more movable water. In a well area with good sealing capability, the right peak of the NMR logging $\mathrm{T}_{2}$ spectrum of the coal seam roof and floor is low, the $T_{2}$ spectrum peak amplitude is low, and there are low porosity and poor permeability. NMR logging technology can be used to evaluate the CBM (coalbed gas reservoir) effectively, and then correctly evaluate and effectively develop the CBM reservoir.
\end{abstract}

Keywords: CBM reservoir; nuclear magnetic resonance; pore structure; porosity; permeability; aquosity; sealing capability

\section{Introduction}

The pore-fracture system development characteristics, aquosity and sealing capability of the roof and floor of coal reservoirs are the main bases for selecting favourable reservoirs in the CBM exploration stage and are important reference indexes for developing a drainage gas recovery plan in the CBM development stage [1, 2]. Coal is a porous media with a complex pore structure that is controlled by several parameters [3-5]. The pore structure and pore characteristics of coal largely determine the ability for gas adsorption and permeability [6]. Therefore, several methods are applied by various researchers [7-10].Existing researches have focused on evaluating the pore structure of coal reservoirs using NMR experimental results [11]. NMR can evaluate the reservoir pore structure of coal and determine the porosity and permeability of coal reservoirs [12]. However, the physical parameters, aquosity of the coal reservoir, and sealing capability of the roof and floor are comparatively rarely researched using NMR logging data.

The Qinshui basin contains a developed medium-high rank coal in which the burtial depth beneath surface is about 600-1000 meters. The CBM occurrence condition is superior, but the pore-fracture is poorly developed and the coal reservoir has low porosity, low permeability and high heterogeneity characteristics. These characteristics have higher requirements to evaluate the pore-fracture system, aquosity and sealing capability of the roof and floor of the coal reservoir[13]. These features allow to test applicability of the NMR technique in determination of porosity and permeability of coal. This paper makes full use of the technical advantages of NMR logging in the study of coal reser-

\footnotetext{
*Corresponding Author: Zhi-di Liu: School of Earth Sciences and Engineering, Xi'an Shiyou University, Xi’an, 710065, China, E-mail: liuzhidi@xsyu.edu.cn

Jing-zhou Zhao, Peng Zhang, Jia-xing Sun: School of Earth Sciences and Engineering, Xi'an Shiyou University, Xi'an, 710065, China
} 
voirs to research the pore structure, physical parameters, aquosity of a coal reservoir and the sealing capability of the roof and floor. For this propose, 7 coal samples, which were obtained from two CBM wells drilled in the Qinshui basin, were investigated by the means of NMR. The research of this paper provides a theoretical basis and technical support with efficient and reasonable development of CBM to develop new technical means for reservoir evaluation in China's CBM exploration and development.

\section{Geological setting}

The CBM field in Zhengzhuang (Central China) was chosen for the coal reservoir evaluation in this study (Figure 1). This CBM field is located at the southern edge of the Qinshui basin (Central China). The overall structure of the studied district is a horseshoe-shaped slope, with broad and gentle strata and an average dip of approximately $4^{\circ}$. The main tectonic formation of this district comprises a series of folds. Few faults have developed, and the fault scale is relatively small. In the southwest of the studied district, the Sitou normal fault and Houchengyao normal fault are formed.

The coalbearing stratigraphic column of the CBM field is illustrated in Figure 2, created by means of the geophysical logging data and drilling data. The total thickness of the coal-bearing strata in each CBM field is approximately $600 \mathrm{~m}$ and comprises the Taiyuan Formation of Upper Carboniferous and the Shanxi Formation of the Lower Permian. The coal in the Taiyuan Formation was poorly developed with a thinner thickness. The Shanxi Formation was developed with a thicker thickness. The thickness of the coal seams in these formations is approximately $8 \mathrm{~m}$ in total, including several main coal seams, e.g. No. 3 and 15 in the Zhengzhuang CBM field. The thickness of these main coal seams is approximately $3.5 \mathrm{~m}$, consisting of anthracite and lean coal and characterized by moderate ash content which is between $8 \% \sim 32 \%$, poor conductivity, and low density.

\section{Evaluating the pore structure of a coal reservoir}

\subsection{Introducing the material and methods}

In the study area, there are three wells with NMR logging, which are well ZS39, ZS50 and ZS25. The NMR analysis and

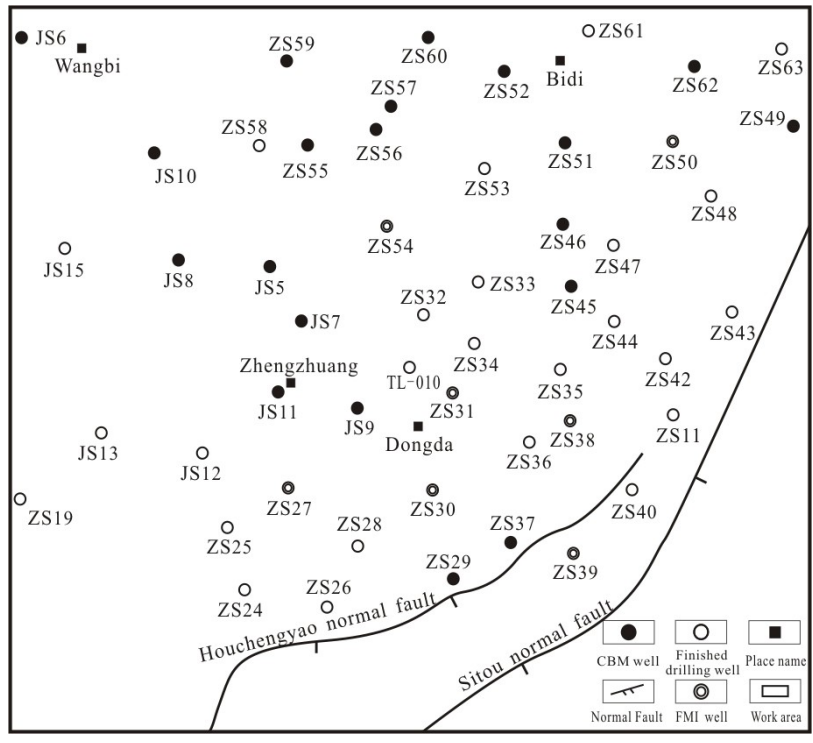

Figure 1: The location map of the work area and the well

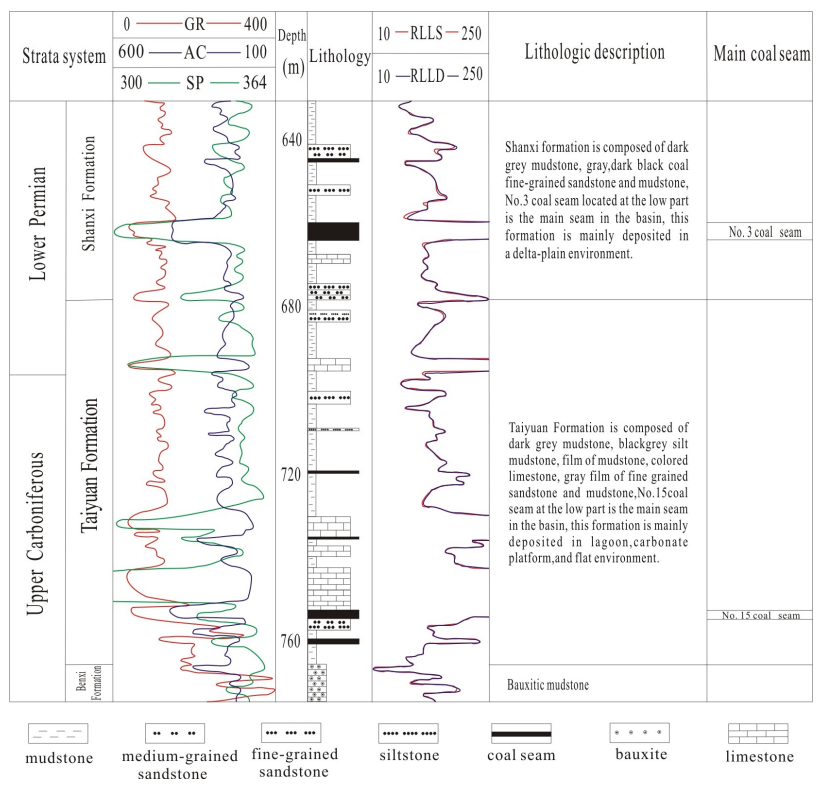

Figure 2: Coalbearing stratigraphic column of Zhengzhuang CBM fields in Qinshui basin

testing of coal samples were carried out in two wells, which are well ZS50 and ZS54.

The adsorption ability of micro and meso pores in coal is strong, but the connectivity is poor, which is not conducive to CBM desorption [4]. The structure of micro and meso pores in coal reservoirs can ensure that the reservoir has good gas accumulation but can also produce a seepage bottleneck, which is not conducive to CBM production [1].

Pore systems with different pores in coal have different relaxation characteristics. The NMR signal is the result of signal superposition in different pore systems. The 
$\mathrm{T}_{2}$ spectra of NMR are obtained by the exponential fitting method, so the $T_{2}$ spectrum reflects the distribution of the pore. Based on the principle of NMR, the collision probability of water molecules in different pore is different, so the influence of surface relaxation is also different, which is related to the specific surface area of the pore [14]. Therefore, the transverse relaxation time of coal can be expressed as equation (1).

$$
\frac{1}{T_{2}}=\frac{1}{T_{2} b}+\rho \frac{S}{V}
$$

Where $T_{2}$ is the transverse relaxation time of coal, ms; $T_{2} b$ is the free relaxation time of fluid in the pore, ms; $S / V$ is the specific surface area of coal, which is inversely proportional to the pore radius; and $\rho$ is the surface relaxivity of coal, which is a parameter used to characterize the coal and rock properties, $\mu \mathrm{m} / \mathrm{ms}$.

Because the $T_{2} b$ value is usually above $3000 \mathrm{~ms}$, $T_{2} b>T_{2}$, that is, the contribution of free relaxation is much smaller, and $\frac{1}{T_{2} b}$ can be ignored. $S / V$ depends on the pore shape of the coal. If the pore radius is proportional to the throat radius, formula (1) can be written as follows.

$$
\frac{1}{T_{2}}=\rho \frac{F s}{r}
$$

Where Fs is the factor of the pore shape, dimensionless; $r$ is the pore radius, $\mu \mathrm{m}$.

Formula (2) shows that the higher the value of the $\mathrm{T}_{2}$ measurement is, the greater the corresponding pore radius is. The lateral surface relaxation strength is constant, usually $1 \mu \mathrm{m} / \mathrm{ms} \leq \rho \leq 30 \mu \mathrm{m} / \mathrm{ms}$, so the corresponding relationship between the transverse relaxation time and the pore radius is established by formula (2).

Previous studies have indicated that the distribution of the pore throat radius has a good correlation with the $\mathrm{T}_{2}$ spectrum distribution $[11,15]$. The peaks of the $\mathrm{T}_{2}$ distribution correspond to the maximum radius, and the troughs of the $\mathrm{T}_{2}$ distribution correspond to the minimum pore throat radius. The $T_{2}$ spectrum distribution can range from less than $1 \mathrm{~ms}$ to $10,000 \mathrm{~ms}$; the large range is caused by the distribution of the pore in the coal reservoir. The fluid in the large pores corresponds to a large $T_{2}$ value, and the fluid in the small pores corresponds to a small $\mathrm{T}_{2}$ value. Therefore, the distribution of the pore structure of coal can be determined by the change of the $\mathrm{T}_{2}$ spectrum.

\subsection{NMR $\mathrm{T}_{2}$ spectrum characteristics of coal}

The NMR relaxation mechanism indicates that the fluid of different types of pores in rock has a different relaxation time, which appears in different positions of the $\mathrm{T}_{2}$ distribution. Accordingly, the pores and the fractures of each level can be distinguished [16]. If the pore-fracture is divided into micropores with a pore of less than $0.1 \mu \mathrm{m}$, meso-macro pores with a pore of more than $0.1 \mu \mathrm{m}$, and fractures, then these three types of pore-fracture type can be identified by the typical $\mathrm{T}_{2}$ spectrum. In addition, according to the $T_{2}$ spectrum distribution characteristics of each NMR signal peak, the development characteristics of the pore-fracture can be determined. Generally, the height of $\mathrm{T}_{2}$ peak reflects the pore diameter, the area of $\mathrm{T}_{2}$ peak reflects the number of a type of pores or fractures, the width of $\mathrm{T}_{2}$ peak reflects the separation of a certain type of pore, and the number of peaks reflects the continuity of the pore.

Figure 3 shows that the scanning electron microscope (SEM) images for well ZS54 in the study area. Figure 4 shows that the NMR experimental results of a coal sample for well ZS54 in the study area. Comparison of Figure 3 and Figure 4 imply that the $T_{2}$ relaxation spectrum of the coal is dominated by a double-peak type. The adsorption pore, seepage pore and fracture of the No.6 coal sample are developed and the peak is higher, which indicates that the connectivity of seepage pores and fractures is very good. The adsorption and seepage pores of the No.7 and No.8 coal samples are developed and the fracture peak is not obvious. From the $\mathrm{T}_{2}$ relaxation time spectrum of coal samples, the ZS54 well mainly develop adsorption pores, seepage pores, and relatively few fractures.

From the length of the relaxation time, the three peaks of the micro pores, the meso and macro pores and the fractures can be identified.

(1) The micropores are mainly distributed between 0.5 $\mathrm{ms}$ and $2.5 \mathrm{~ms}$. The typical characteristics have almost no difference with the two $T_{2}$ spectra before and after centrifugation, which represents adsorption pores; (2) The spectra peak of the meso-macro pores is mainly distributed between $20 \mathrm{~ms}$ and $50 \mathrm{~ms}$. The peak is generally smaller than that of the micropores and represents the seepage pores; (3) The fracture peak is mainly greater than the $100 \mathrm{~ms}$ section, it is only found in the part of coal with fracture development. The more the fracture develops, the higher the peak value is. The analysis results show that the meso pore is the most developed, followed by the macro pore.

The $\mathrm{T}_{2}$ relaxation spectrum of the coal is dominated by the double-peak type, and the continuity between the two peaks is poor. Generally, the relaxation time of the two peaks of the segmentation point is approximately $10 \mathrm{~ms}$. The fluid in the front peak is in the bound state, which reflects the characteristics of the micropores of the coal. The fluid in the behind peak is in a movable state, which reflects the characteristics of the fracture in the coal. For 


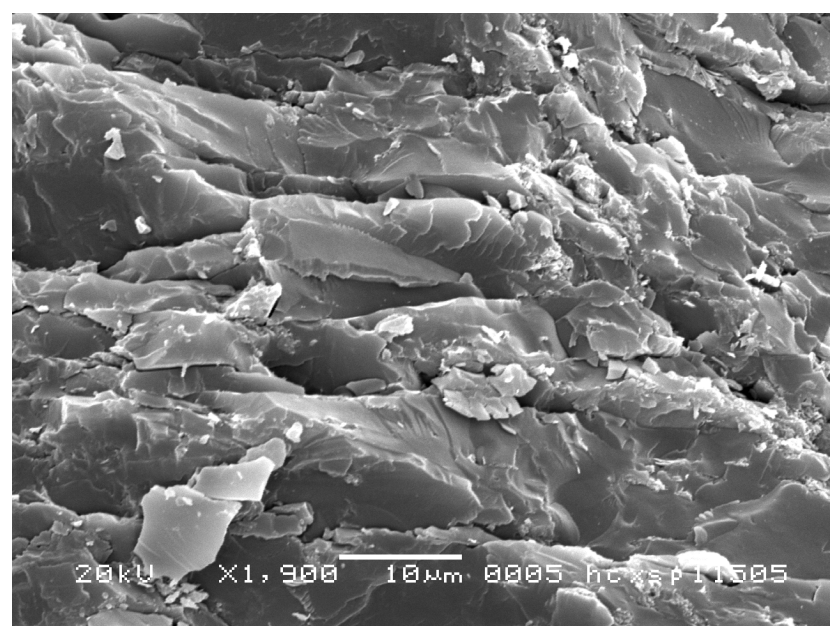

(a) No.6

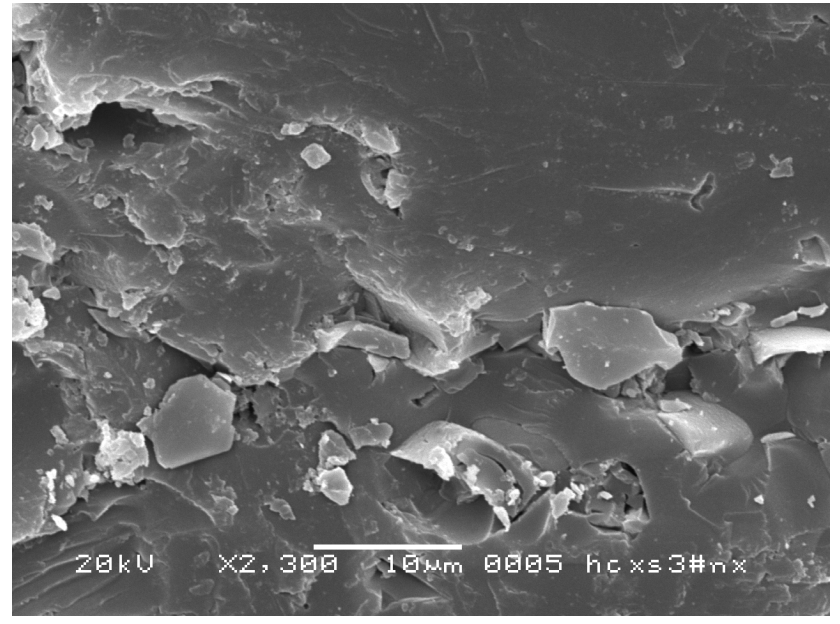

(b) No.7

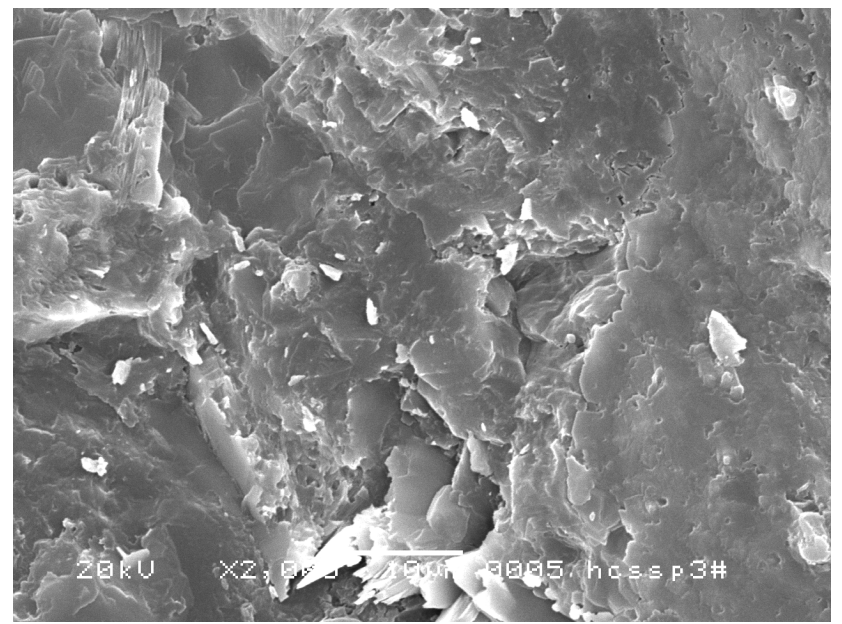

(c) No.8

Figure 3: Scanning electron microscope (SEM) images for well ZS54 in the study area

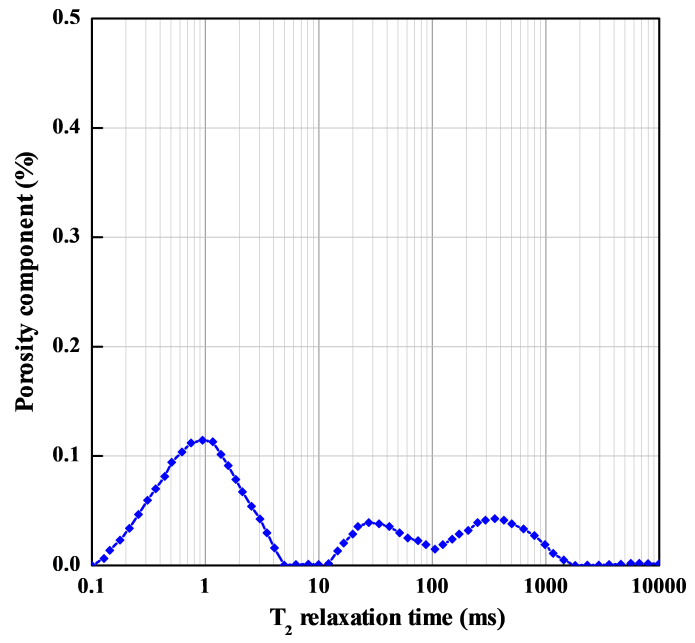

(a) No.6

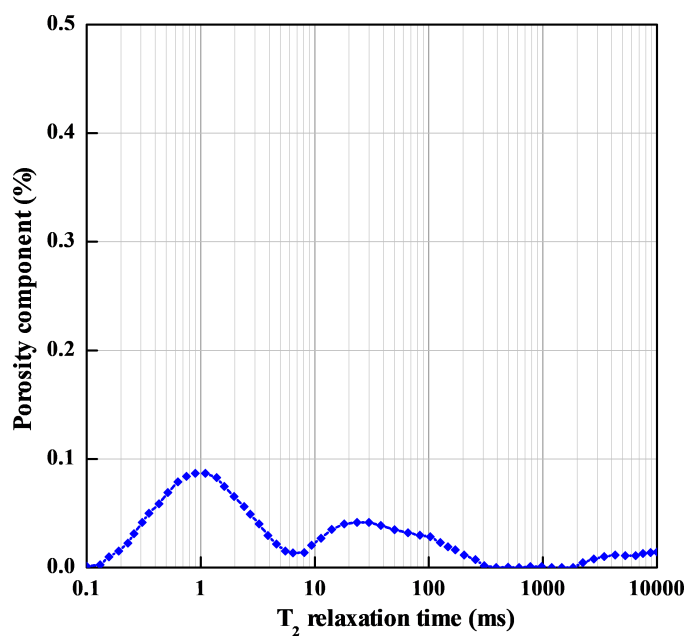

(b) No.7

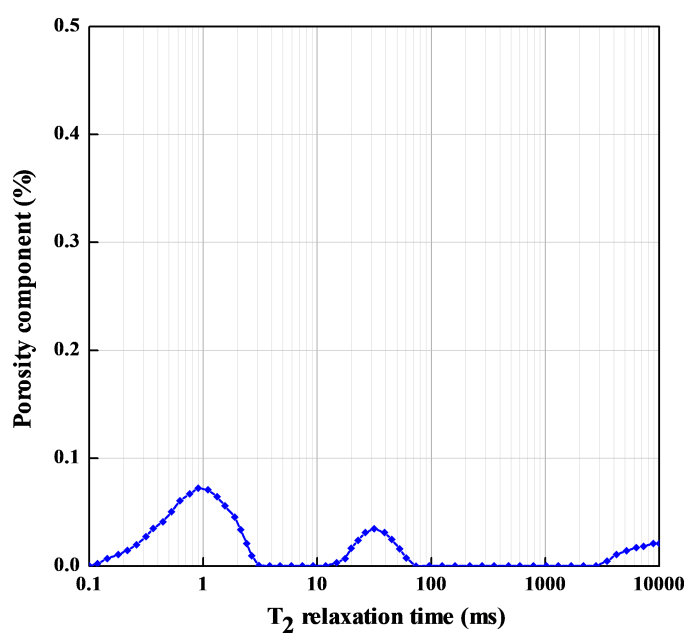

(c) No.8

Figure 4: NMR experimental results of a coal sample for well ZS54 in the study area 
the two peak type and three peak type, the poor continuity between the two peaks reflects that the difference between the pore and fracture is larger and the pore distribution is not continuous, so it is not conducive to the enrichment and migration of CBM. The good continuity between the two peaks reflects that the difference between the pore and fracture is smaller and the pore distribution is continuous, which is favorable for the enrichment and migration of CBM.

\subsection{Analyzing the pore structure of coal reservoirs based on the NMR logging $T_{2}$ spectrum}

Figure 5 shows the evaluation results of the pore structure for well ZS25 using the NMR logging data, and shows that the $\mathrm{T}_{2}$ spectrum relaxation time of \# 3 coal is approximately 0.5-100 ms, which reflects that the coal mainly develops micro, meso and macro pores. In addition, fractures are also developed. The distribution of seepage pores and fractures is not continuous, which indicates that the CBM liquidity is poor. CBM mainly occurs in meso pores in the adsorption state, which is not conducive to CBM migration. The $\mathrm{T}_{2}$ relaxation time spectrum of coal in the study area is dominated by the double-peak type, the continuity between the two spectral peaks is poor, and the segmentation point between the two peaks is approximately $10 \mathrm{~ms}$. There is a clear gap between the two peaks of the coal reservoir, which shows that the irreducible water and the movable fluid cannot communicate effectively.

According to the NMR $\mathrm{T}_{2}$ spectrum in the study area, the pore of coal reservoirs can be divided into two types. Type one is micropore, and the meso-macro pore and fracture are relatively undeveloped; the other is mainly mesomacro pore, and the micropore pore is relatively undeveloped. In the coal reservoir of the study area, the adsorption capacity of micro and meso pores is strong, but the connectivity is poor, which is not conducive to CBM desorption. The seepage bottleneck caused by the micro and meso pores is unfavorable to the production of CBM.

Overall, the general characteristic of the pore system structure of the coal reservoir in the study area is the most development of micropores, and least development of macro pores. In some coal reservoirs, the meso pores are the most developed, followed by micropores, with the macro pores undeveloped. The pore throat distribution of the coal reservoir is different; the pore-throat collocation of some coal reservoirs is not reasonable. There is minimal pore volume in some pore segments, which can result

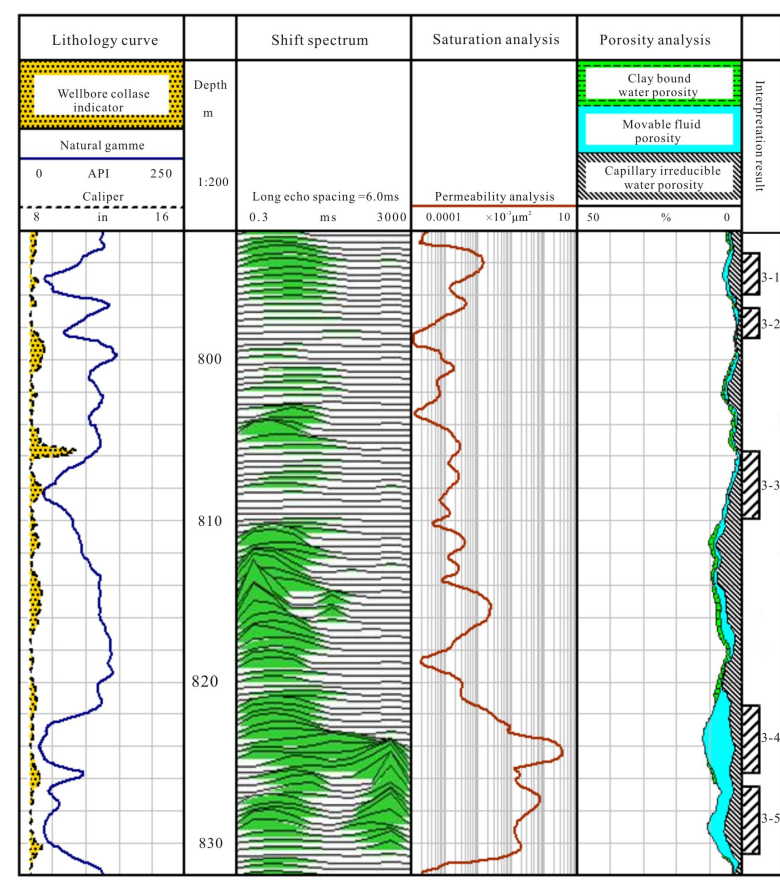

Figure 5: Evaluation results of the pore structure for well ZS25 using NMR logging data

in channel discontinuity of the fluid output and the phenomenon of penetration bottleneck.

\section{Evaluating the physical properties of the coal reservoir, roof and floor}

\subsection{Introducing the NMR analysis principle of the physical properties of coal reservoirs}

According to the NMR principle, the $T_{2}$ spectrum represents the NMR amplitude of ${ }^{1} \mathrm{H}$ in a certain period of time. Therefore, the maximum amplitude of the cumulative $T_{2}$ spectrum under the condition of saturated water can be used to calibrate the total porosity. Second, under the condition of residual water, the $\mathrm{T}_{2}$ spectrum is obtained after analyzing the coal sample. Similarly, the $\mathrm{T}_{2}$ spectrum is converted to a cumulative $\mathrm{T}_{2}$ spectrum and the cumulative relaxation amplitude varies with the relaxation time. Through normalized processing, the maximum amplitude value of the cumulative $T_{2}$ spectrum under the condition of residual water can be used to calibrate the residual poros- 
ity. The difference between the total porosity and the residual water porosity is the effective porosity.

To evaluate the porosity of the coal reservoir accurately, it is necessary to determine whether the NMR porosity is the total porosity or the effective porosity. Generally, when the echo time is less than $0.3 \mathrm{~ms}$, capillary-bound pores can be measured, so the measured porosity is the total porosity; when the echo time is larger than $0.3 \mathrm{~ms}$, the information of the micropores is lost, so the measured porosity is equivalent to the effective porosity. For porosity, the higher amplitude and larger peak area of $\mathrm{T}_{2}$ spectrum reflect higher porosity, the higher amplitude and closer right of $\mathrm{T}_{2}$ spectrum reflect the amount of macro pores, so the physical properties are better.

Permeability is an important parameter to characterize coal reservoirs, which directly determines the production of CBM. Based on the correlation analysis between the permeability and NMR characteristics, the corresponding permeability model is established. According to the capillary flow law and Brownstein-Tarr relaxation theory established by the relationship between the coal reservoir permeability and the coal pore structure [18], the NMR permeability of the coal is as follows.

$$
K=\frac{\varphi^{3}}{2}\left(\frac{T 2 \ln \rho_{2}}{\tau}\right)^{2}
$$

Where $K$ is the NMR permeability of the coal reservoir, $10^{-3} \mu m^{2} ; \varphi$ is the coal reservoir porosity, $\% ; \tau$ is the bending factor, dimensionless; $T 2 \mathrm{~lm}$ is the logarithmic average value of $T_{2}$ distribution, ms; and $\rho_{2}$ is the transverse relaxation strength of the coal particle surface, $\mu \mathrm{m} / \mathrm{ms}$.

According to equation (3), the difference in the pore structure determines the variation of the spectral distribution. Thus, the NMR spectrum and the coal pore structure have a corresponding relationship, and the pore and the distribution characteristics of coal are the main factors that affect the permeability of coal reservoirs. Therefore, from a theoretical point of view, the distribution of $\mathrm{T}_{2}$ spectrum has a good relationship with the macro permeability and the micropore structure of the coal reservoir. Macro pore throats correspond to larger $\mathrm{T}_{2}$ values, meso pores correspond to smaller $T_{2}$ values, and the peak interval on the pore throat distribution curve corresponds to the peak interval of the NMR porosity.

\subsection{Analyzing the NMR experimental results of the coal reservoir}

In this study, the porosity and permeability of four coal samples for ZS50 well were tested. The experiment results of the NMR test are shown in Table 1 . The porosity of the coal reservoir is small, and the permeability is poor. The NMR experimental results show that the effective porosity of \#3 and \#15 coal in the study area is low and the effective porosity of the analysis well is generally less than $3 \%$. These results reflect the matrix pores of the coal, and fracture and macro pores have little contribution to the porosity. In all of the samples, the porosity is less than $4.5 \%$ and the permeability is less than $0.01 \mathrm{mD}$.

Table 1: NMR experimental results of the porosity and permeability of coal for well ZS50

\begin{tabular}{ccccc}
\hline $\begin{array}{c}\text { Sample } \\
\text { No. }\end{array}$ & $\begin{array}{c}\text { Coal } \\
\text { No. }\end{array}$ & $\begin{array}{c}\text { Depth } \\
(\mathrm{m})\end{array}$ & $\begin{array}{c}\text { Porosity } \\
(\%)\end{array}$ & $\begin{array}{c}\text { Permeability } \\
\left(10^{-3} \mu \mathrm{m}^{2}\right)\end{array}$ \\
\hline 6 & $\# 3$ & 696.4 & 1.76 & 0.003 \\
7 & $\# 3$ & 697.66 & 1.52 & 0.003 \\
8 & $\# 3$ & 698.8 & 0.81 & 0.001 \\
16 & $\# 15$ & 794.14 & 2.11 & 0.004 \\
\hline
\end{tabular}

\subsection{Analyzing the physical characteristics of the coal reservoir, roof and floor based on NMR logging}

Recent researches demonstrate that the pore and the fracture characteristics of the coal reservoir can be determined by the $T_{2}$ spectrum distribution characteristics of each NMR signal peak. Generally, the closer the $T_{2}$ spectrum peak is to the $T_{2}$ values, the smaller the pore of the reservoir is.

Figure 6 shows that the evaluation results of the physical properties of the coal reservoir and its roof and floor for well ZS50 using the NMR data. This figure shows that the $\mathrm{T}_{2}$ relaxation spectrum shape of \#15 coal reservoir is close to the right, the relaxation speed is slow, and the relaxation time is long. The meso-macro pores are developed, most of the fluid is in the moving state, and the characteristics of the reservoir are good. The fluid characterized by the front peak is in the bound state, which reflects the characteristics of the micropores of the coal. The fluid characterized by the behind peak is in a movable state, which mainly reflects the characteristics of the fracture in the coal. Most of the fluid is in the bound state, which is a characteristic of a poor reservoir. The content of movable fluid is high, and the permeability is good. Overall, the behind peak of the $\mathrm{T}_{2}$ NMR curve of the coal reservoir in the study area is relatively developed, and the left or the middle peak is not developed, that is, the coal sample is dominated by fractures and the fractures are relatively welldeveloped. The sample also contains some micro, meso and macro pores that are not fully developed. The continuity between the peaks is good, and the distribution of 
pores and fracture size is continuous. The connectivity of all types of pores is good, so the movable fluid saturation is higher. The permeability of the coal is better; thus, it is conducive to the enrichment of CBM.

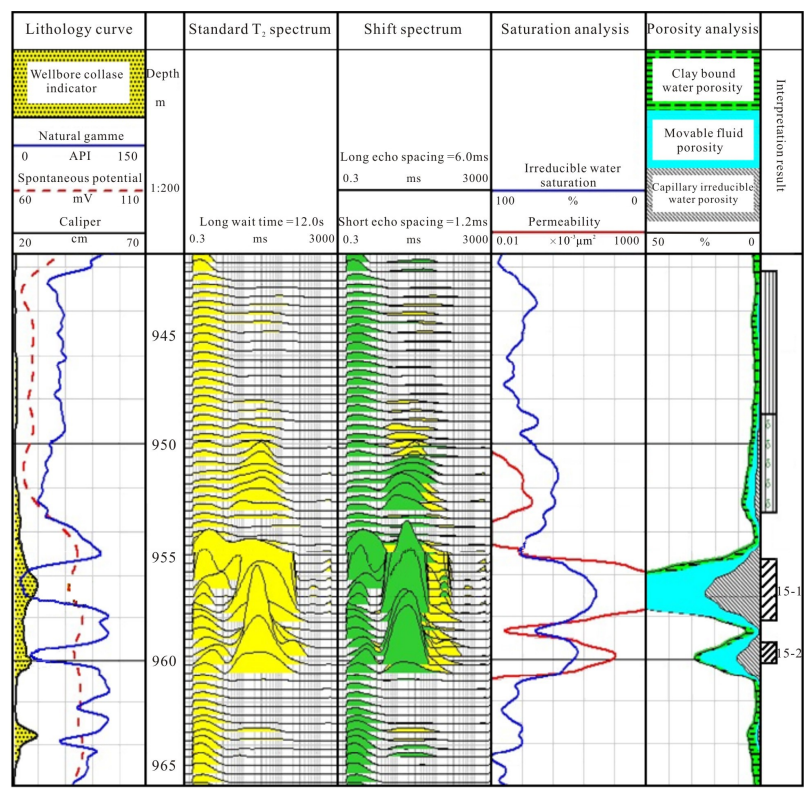

Figure 6: Evaluation results of the physical properties of the coal reservoir and the roof and floor for well ZS50 using the NMR data

As shown in Figure 6, \#15 coal seam roof for the ZS50 well is a mudstone layer, the amplitude of the standard $\mathrm{T}_{2}$ spectrum peak is low, and the NMR porosity is small, approximately $3 \%$. The permeability is poor and is less than $0.01 \times 10^{-3} \mu \mathrm{m}^{2}$. The upper part of \#15 coal seam roof is sandstone, which has a double-peak $\mathrm{T}_{2}$ spectrum and high amplitude, indicating macro pores and good permeability. The NMR logging interpretation result shows that the porosity is $8.23 \%$ and the permeability is $0.22 \times 10^{-3} \mu \mathrm{m}^{2}$. From the analysis of the interval porosity, the pore distribution is mainly in the 16-64 ms range, and the pore distribution is mainly in the micro to meso range. The porosity of \#15 coal seam floor is not developed. The porosity is low and less than $2 \%$. The permeability is poor and less than $0.01 \times 10^{-3} \mu \mathrm{m}^{2}$.

On the whole, the borehole of the roof and bottom in $\# 15$ coal reservoir of the well is regular, $T_{2}$ spectra of NMR logging are distributed in 8 bins and bins 1 4 are a single peak. Therefore, there are few pores and a small amount of macro pores, the effective porosity is not developed, and the permeability is poor. The old roof has the characteristics of a double-peak, indicating a moderate pore distribution. There are both micropores and macro pores, and the macro pore is controlled by the micropores. Therefore, the physical properties of the reservoir are poor. However, compared with the direct roof and floor, the physical properties are better.

\section{Evaluating the aquosity of the coal seam roof and floor}

The circulating fluids in the coal is mainly in the pores and fractures, so the development of pores and fractures determines the physical properties of the coal and influences the aquosity of the coal. The natural structural fractures in coal can lead to hydrodynamic activity; the alternation of water will take the CBM from the coal, leading to the reduction of the gas content in the coal and directly affecting the CBM production [17]. If the coal has good aquosity and the hydrodynamics are stronger, it will be harder to drain methane from the coal bed. Therefore, it is important to determine the aquosity of the coal.

Based on the basic principles of NMR, a macro pore throat corresponds to a long $\mathrm{T}_{2}$ relaxation time and a small pore throat corresponds to a short $\mathrm{T}_{2}$ relaxation time. The larger the average value of the $\mathrm{T}_{2}$ relaxation time is, the better the physical properties is, and the greater the water content is.

Figure 7 shows that the evaluation results of the aquosity of the coal reservoir for well ZS39 using the NMR data. The NMR $\mathrm{T}_{2}$ spectrum of well ZS39 indicates that the left peak is high, the right peak is low in the direct roof and floor of \#15 coal, and the pores are the compound type. Almost no development of the right peak indicates that the pore type and effective throat are tiny and micro, respectively. The contribution rate of the throat permeability is single-peaked; the pore-throat cannot provide greater fluid flow, which indicates that the aquosity is poor. The NMR $\mathrm{T}_{2}$ spectrum of the old floor of the coal has a high right peak, which indicates that the pore type is mainly meso-macro pores and the primary intergranular pores and secondary pores are developed. The distribution of the pores and throat has a double pore structure, and the throat permeability contribution rate is double-peak, which provides better reservoir and percolation space for the fluid and higher aquosity.

The direct roof in the ZS39 well at an interval of 1011.8 to $1014 \mathrm{~m}$ is mudstone that is relatively thin. The NMR logging data interpretation indicates that the aquosity of the direct roof and floor is poor and that the aquosity of the old floor is good (Figure 7). The well is far from the fault zone and the low amplitude zone of the structure, indicating that the influence of the fracture and the structural ampli- 


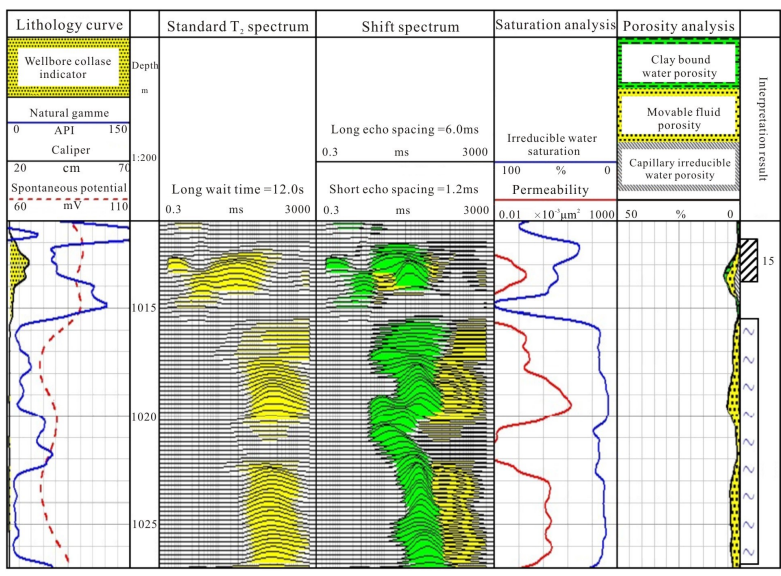

Figure 7: Evaluation results of the aquosity of the coal reservoir for well ZS39 using the NMR data

tude on the water yield is small. The old floor of the coal is sandstone, with the pores and fractures, and the aquosity of rock is enhanced. The direct bottom is a thin mudstone, and the fracturing easily presses through the direct floor and connect to the aquifer of the old floor. Therefore, the water yield increases during drainage gas recovery. The gas content by coal core analysis is $5.64 \mathrm{~m}^{3} / \mathrm{t}$, the daily gas production is $1281 \mathrm{~m}^{3}$, and the daily water production is $14 \mathrm{~m}^{3}$. The water is mainly from the sandstone of old floor, rather than the coal itself.

\section{Evaluating the sealing capability of the coal seam roof and floor}

A good seal-cap rock is the basic condition of CBM storage. This study shows that there are 4 main factors influencing the sealing capability of the coal seam roof and floor. The first is lithology: with the increase of the sand content, the seal of the roof and floor rocks becomes worse. The second is the thickness of the strata: with the increase of the thickness of the sandstone in the roof and floor, the sealing capability becomes worse, but with the increase of the thickness of mudstone in the roof and floor, the sealing capability becomes better. The third are the physical properties, which are the porosity and permeability: as the physical properties improve, the sealing capability becomes worse. The fourth are the fracture development characteristics: better development degree of fracture corresponds to worse sealing capability [17].

Figure 8 shows that the evaluation results of the sealing capability of the coal reservoir and its roof and floor for well ZS50 using the NMR data. This figure implies that the
$\mathrm{T}_{2}$ spectrum of the direct roof mudstone section on \#3 coal is micropores or meso pores and that the pore structure is relatively simple. In the well section with the better borehole, the effective porosity of NMR is less than $3 \%$ and the permeability is less than $0.01 \times 10^{-3} \mu \mathrm{m}^{2}$. The $\mathrm{T}_{2}$ spectrum of the direct floor mudstone section under \#3 coal is the micro-meso pore. The $T_{2}$ spectrum of the sandstone under the mudstone is meso- macro pores, the amplitude of standard $\mathrm{T}_{2}$ spectral peak is low, the NMR porosity is approximately $3 \%$, and the permeability is poor and less than $0.05 \times 10^{-3} \mu \mathrm{m}^{2}$. The pore structure of the roof layer in \#3 coal is relatively simple, and develop micropore and meso pore. The pore structure of the floor is relatively complex, and develops micropores and meso pores, which indicates that the sealing capability of the roof layer is better than that of the floor layer in \#3 coal.

The logging description and conventional logging lithology interpretation denote that the floor layer of the coal reservoir is mudstone or sandy mudstone, and that the thickness is $5 \mathrm{~m}$ and that the lithology is compact, so it is a good sealing layer. The core analysis of the well shows that the gas content is $28.5 \mathrm{~m}^{3} / \mathrm{t}$ and the gas content calculated by using the logging data is $24.45 \mathrm{~m}^{3} / \mathrm{t}$. Fracturing and development show that the daily gas production is $2238 \mathrm{~m}^{3}$, and the daily water production is $0.3 \mathrm{~m}^{3}$. The sealing capability of the roof and floor layer is better, and the CBM adsorption of the coal is completely sealed.

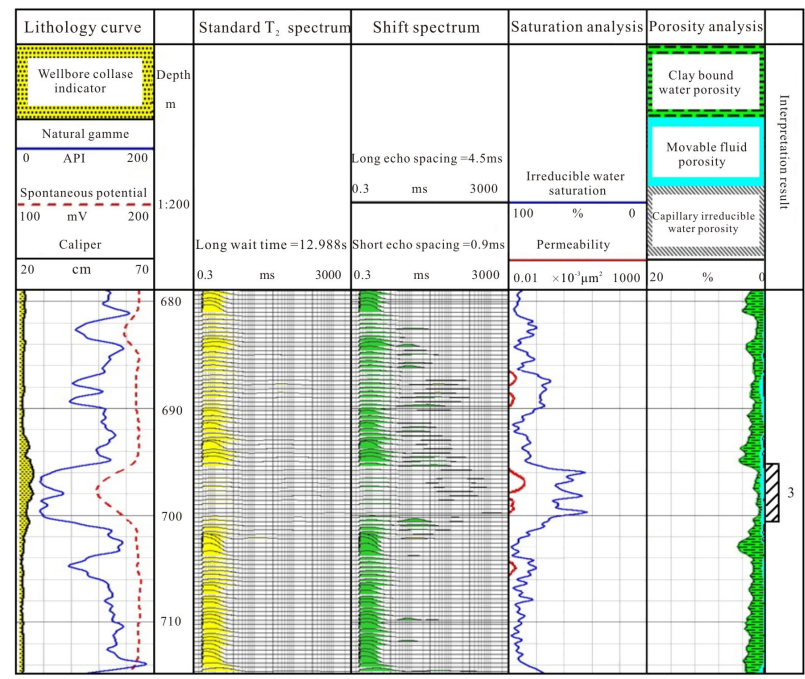

Figure 8: Evaluation results of the sealing capability of the coal reservoir and the roof and floor for well ZS50 using the NMR data

Overall, the NMR $T_{2}$ spectra of the roof and floor of coal in the study area are mostly single peaks, and the amplitude of spectrum peak is low or non-existent. There- 
fore, effective porosity is not developed, the permeability is poor, and there is a good sealing layer.

\section{Discussion}

Through the results of the NMR $\mathrm{T}_{2}$ distribution method, the $T_{2}$ distribution is a better representation of the pore distribution. NMR relaxation can distinguish a greater range, which comprises not only the macro pores but also the micropores, which are smaller than those of the throat. Therefore, NMR $T_{2}$ distribution is a good way to analyze the distribution of coal pores.

The fracture in the coal reservoir provides reservoir space and also provides favorable conditions for the communication of the pore and an increase of the flow passage. The $T_{2}$ relaxation time spectrum can qualitatively identify the physical properties of the coal reservoir. Greater development of fracture in the coal reservoir caused greater development of the behind peak in the $\mathrm{T}_{2}$ relaxation time spectrum and better seepage effect of the coal reservoir, which is more favorable to develop CBM. The effective porosity of a coal reservoir calculated by the NMR method has great significance in evaluating the coal permeability.

In general, the greater the development of the pores and fractures in the coal is, the stronger the aquosity is. Compared with the aquifer of roof and floor of sandstone, due to the small void space of the coal, the water content in the coal is small. Therefore, NMR logging can effectively reflect the porosity and fracture development of the coal. Also, it can be used to analyze the aquosity of the coal and the roof and floor.

NMR logging can directly provide the effective porosity and permeability of the coal seam roof and floor. The sealing capability evaluation of the coal seam roof and floor is performed using the physical property, and the pore structure of the coal seam roof and floor is reflected by the NMR $\mathrm{T}_{2}$ spectrum.

\section{Conclusions}

The results are revealed from this study as follows:

1. The $T_{2}$ relaxation time spectrum reflects the pore structure characteristics of the coal. In the $\mathrm{T}_{2}$ spectra of the coals, the three $\mathrm{T}_{2}$ peaks, $0.5 \sim 2.5,20 \sim 50$ and $>100 \mathrm{~ms}$, correspond to micropores, large pores and the fractures, respectively. The $\mathrm{T}_{2}$ spectrum of the coal in the study area is a double-peak structure, and there are a clear gap and poor continuity between the two peaks, which indicates that there is no effective seepage between the irreducible water and the movable fluid in the coal reservoir.

2. NMR can reflect the level of porosity and permeability of the coal reservoir. Greater development of fracture and better permeability in the coal reservoir cause greater right peak of $\mathrm{T}_{2}$ relaxation time spectrum of the NMR. The effective porosity of coal reservoirs in the study area is generally less than $3 \%$, which reflects the matrix pores of the coal. The fractures of large pore have little contribution to the porosity.

3. The high left peak and low right peak of the $\mathrm{T}_{2}$ spectrum show that the pores are mainly meso pores and micropores with some meso pores and large pores, so there are more ineffective pores that can provide fluid seepage and the amount of movable water is less. The low left peak and high right peak indicate the development of meso pores and large pores with some tiny pores and micropores, so it provides a percolation space for the fluid and the amount of movable water is more.

4. The $T_{2}$ spectrum of the NMR logging of the roof and floor of the coal reservoirs in study area is mainly the left peak, the $T_{2}$ relaxation time is short, and the spectrum peak is low, then the NMR porosity is small, the permeability is poor, and the sealing capability of roof and floor of the coal reservoirs is good.

Acknowledgement: The authors would like to acknowledge the reviewers and the editor for their many helpful comments and suggestions, which significantly improved the manuscript. Thanks are also given to the key laboratory of science research project in Shaanxi province department of education (Grant NO: 14JS082; 14JS084) and the foundation research project of natural science in Shaanxi Provincial (Grant NO: 2013JQ5008) for their support during the completion of this paper.

\section{References}

[1] Zuber M.D., Production characteristics and reservoir analysis of coalbed methane reservoirs. (1998), International Journal of Coal Geology 38(1), 27-45

[2] Solano-Acosta W., Mastalerz M., Schimmelmann A., Cleats and their relation to geologic lineaments and coalbed methane potential in Pennsylvanian coals in Indiana. (2007), International Journal of Coal Geology 72(3), 187-208

[3] Clarkson, C.R., Bustin, R.M., Variation in micropore capacity and size distribution with composition of Cretaceous coals of the Western Canadian Sedimentary Basin. (1996), Fuel 75(13),14831498

[4] Mastalerz, M.,Drobniak, A.,Rupp, J., Meso and micropore char- 
acteristics of coal lithotypes: Implication for $\mathrm{CO}_{2}$ adsorption. (2008), Energy\&Fuels 22(6),4049-4061

[5] Mastalerz, M., Drobniak, A., Walker, R., Morse, D.,Coal lithotypes before and after saturation with $\mathrm{CO}_{2}$; insights from microand mesoporosity, fluidity, and functional group distribution. (2010), International Journal of Coal Geology 83(4),467-474

[6] Karayiğit, A.I.., Mastalerz, M., Oskay, R.G., Querol, X., Lieberman, N.R., Meso- and microporosity of the subbituminous kM2 coal seam (Soma, Turkey) and its relationship with coal characteristics.( 2017), International Coal Geology 184(1), 73-87.

[7] Clarkson, C.R., Bustin, R.M., Variation in permeability with lithotype and maceral composition of cretaceous coals of the Canadian cordillera. (1997), International Journal of Coal Geology 33(2),135-151

[8] Moore, T.A., Coalbed methane: A review. (2012), International Journal of Coal Geology 101(6),36-81

[9] Rodrigues, C.F., Lemos de Sousa, M.J.,The measurement of coal porosity with different gases. (2002), International Journal of Coal Geology 48(3-4),245-251

[10] Yao Y., Liu D., Che Y., Tang D., Tang S., Huang W., Non-destructive characterization of coal samples from China using microfocus $X$ ray computed tomography. (2009), International Journal of Coal Geology 80(2),113-123

[11] Xie S.B., Yao Y.B., Chen J.Y., Yao W., Research of micro-pore structure in coal reservoir using low-field NMR. (2015), Journal of the China Coal Society 40(s1),170-176 (in Chinese)
[12] Harmer J., Callcott T., Maeder M., Smith B.E., Novel approach for coal characterization by NMR spectroscopy: Global analysis of proton $\mathrm{T}_{1}$ and $\mathrm{T}_{2}$ relaxations. (2001), Fuel 80(3),417-425

[13] Su X.B., Lin X.Y., Zhao M.J., Song Y., Liu S.B., The upper Paleozoic coalbed methane system in the Qinshui basin, China. (2005), AAPG Bulletin 89(1),81-100

[14] Yuko M., Hiroyuki I., Gen K., Application of solid-state NMR to coal. (2009), Journal of the Japan Institute of Energy 88(2),102107

[15] Kevin M., Douglas M., Smith A., NMR technique for the analysis of pore structure: Numerical inversion of relaxation measurements. (1987), Journal of Colloid \& Interface Science 119(1),117126

[16] Pape H., Clauser C., Improved interpretation of nuclear magnetic resonance $T_{1}$ and $T_{2}$ distributions for permeability prediction: Simulation of diffusion coupling for a fractal cluster of pores. (2009), Pure and Applied Geophysics 166(5),949-968

[17] Lv Y.M., Hu A.M., Tang D.Z., Song B., Liang W., Xu H., Lin W.J., Hu X., Nuclear Magnetic Resonance (NMR) Response of Mobile Water in Coals and Influencing Factors. (2012), Geological Journal of China Universities 18(3),549-552 (in Chinese)

[18] Zodrow E.L., Mastalerz M., Werner-Zwanziger U., D’Angelo J. A., Medullosalean fusain trunk from the roof rocks of a coal seam: insight from FTIR and NMR. (2010), International Journal of Coal Geology 82(5),116-124 